\title{
ERRATUM
}

Bezalel Peleg • Hans Peters

\section{Consistent voting systems with a continuum of voters}

Published online: 4 July 2006

(C) Springer-Verlag 2006

\section{Soc Choice Welfare (2006) DOI 10.1007/s00355-006-0140-0}

The name of the first author, Bezalel Peleg, was given incorrectly. The correct name is given here.

The online version of the original article can be found at http://dx.doi.org/10.1007/s00355-0060140-0.

B. Peleg $(\varangle)$

Institute of Mathematics and Center for the Study of Rationality,

The Hebrew University of Jerusalem, Feldman Building,

Givat-Ram, 91904 Jerusalem, Israel

E-mail: pelegba@math.huji.ac.il

H. Peters

Department of Quantitative Economics, University of Maastricht,

P.O. Box 616, 6200, MD, Maastricht, The Netherlands

E-mail: h.peters@ke.unimaas.nl 